\section{Direct Imaging of Northern Blots on an Optical Scanner Using Ethidium Bromide}

BioTechniques 28:864-870 (May 2000)

Northern blot analysis allows for the study of differential expression of specific mRNAs. This procedure involves the loading of specific amounts of RNA on an agarose gel, the transfer of the RNA from the gel to a nylon membrane and the subsequent analysis of that RNA using radioactively or nonradioactively labeled probes. The many steps involved in RNA preparation and Northern analysis contribute to misestimation of the amount of RNA present in the final analysis. Therefore, it is important to have a reliable control for RNA loading and transfer, particularly if quantitative comparisons are to be made.

Traditionally, relative amounts of RNA have been determined by two methods: either staining the gel or membrane for detection of the $18 \mathrm{~S}$ and $28 \mathrm{~S}$ rRNAs or reprobing the blot for a constitutively expressed "housekeeping" gene. The first method involves staining the gel either by including stain in the sample before loading or staining the entire gel or membrane after electrophoresis. Ethidium bromide is often used for this purpose. A photograph may then be taken of the gel or membrane under illumination with UV light, and the photograph (or its negative) may be scanned and quantitated to determine the relative amount of rRNA in each sample. In this case, scanning the negative itself is more reliable but is subject to the narrow linear range of the film, nonuniformity of illumination by the UV light source and sometimes, the nonuniformity or nonlinearity of the scanning instrument.

The use of charge-coupled device (CCD) array cameras solves some problems by eliminating the use of film. However, quite often there is a significant decrease in intensity at the edges of even the best UV light boxes, which these systems still require. The second method involves the use of a constitutively expressed gene such as glyceraldehyde-3-phosphate dehydro- genase (GAPDH). This requires acquisition of a second hybridization probe, stripping the membrane of the previous probe and labeling, hybridization and autoradiography using the new probe.

We wished to find a faster and more reliable method for determining the relative quantities of RNA in each sample on a Northern blot. We currently use a Storm $^{\mathrm{TM}} 860$ Instrument (Amersham Pharmacia Biotech, Piscataway, NJ, USA) to quantify the expression of specific radiolabeled transcripts on Northern membranes. The ethidium bromide/DNA complex exhibits maximal excitation at $518 \mathrm{~nm}$ and has a maximal emission of $605 \mathrm{~nm}$ (1). Although the $450 \mathrm{~nm}$ maximum of the blue diode light source is far from the excitation maximum for ethidium bromide, the Molecular Dynamics application notes indicate that the instrument can detect ethidium bromide in its blue fluorescence mode. Therefore, we have compared quantitation of RNA on Northern membranes using ethidium bromide and using hybridization of radiolabeled probes using the Storm 860 Instrument for all scans.

Aliquots of total RNA, isolated as

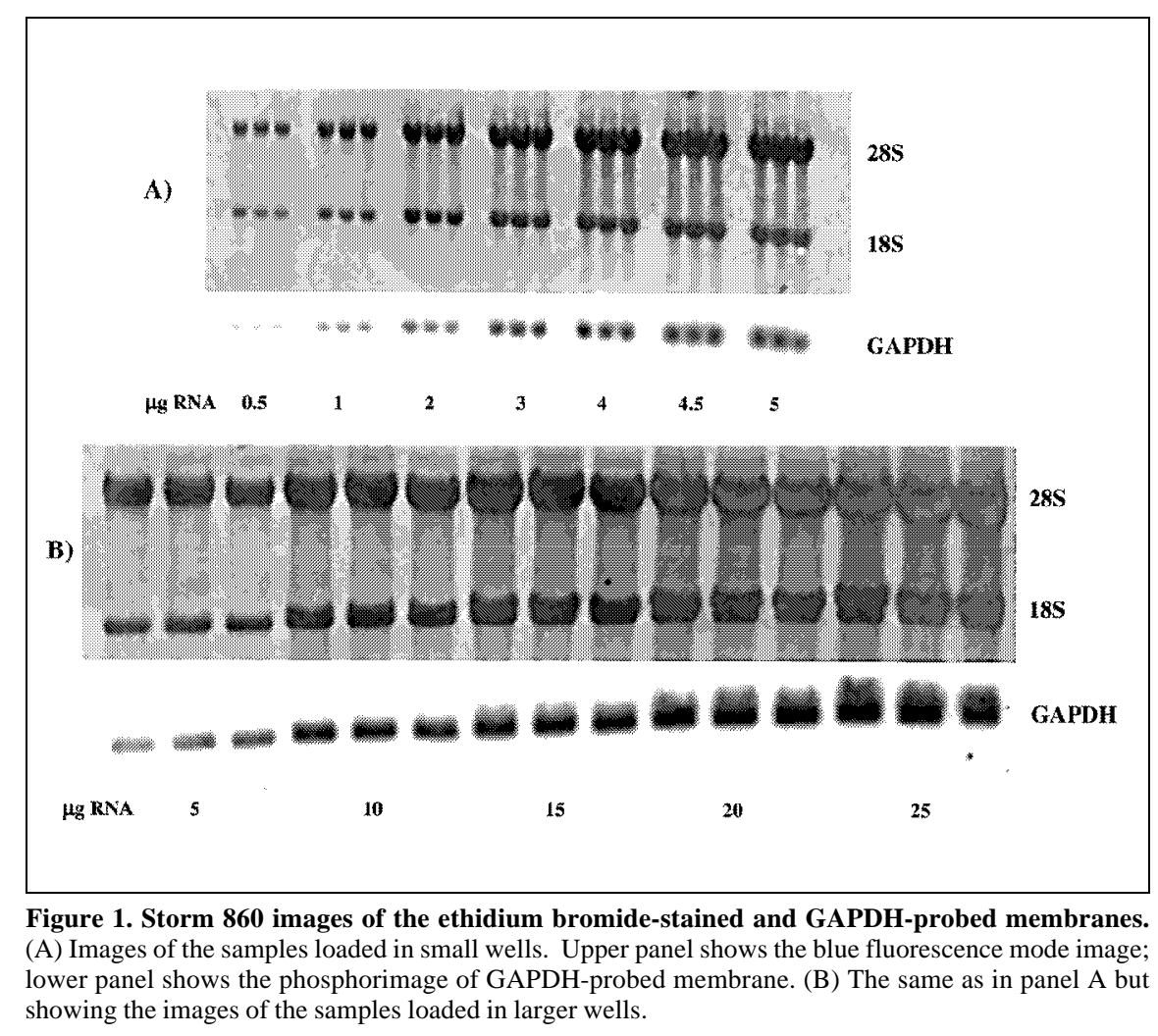

Figure 1. Storm 860 images of the ethidium bromide-stained and GAPDH-probed membranes. (A) Images of the samples loaded in small wells. Upper panel shows the blue fluorescence mode image; lower panel shows the phosphorimage of GAPDH-probed membrane. (B) The same as in panel A but showing the images of the samples loaded in larger wells.

previously described (4) from the amnion-derived WISH cell line (2), were loaded in triplicate in amounts ranging from $0.5-25 \mu \mathrm{g} / \mathrm{lane}$ on a $20 \times 25 \mathrm{~cm}$, $1 \%$ agarose, MOPS-formaldehyde gel (6) in volumes ranging from $16-25 \mu \mathrm{L}$, depending on the size of the well. The samples were electrophoresed for $20 \mathrm{~h}$ at $25 \mathrm{~V}$ (sufficient for bromophenol blue tracking dye to travel $8 \mathrm{~cm})$. We have previously determined (data not shown) that the optimal loading (greatest loading with minimal band broadening and streaking) is $3 \mu \mathrm{g}$ total RNA/ well (small well size) and $15 \mu \mathrm{g}$ total RNA/well (large well size). Even rare messages can be detected with these amounts. Ethidium bromide was added to the sample at a final concentration of $40 \mu \mathrm{g} / \mathrm{mL}$.

Capillary transfer of the RNA to GeneScreen Plus ${ }^{\circledR}\left(\mathrm{NEN}^{\circledR}\right.$ Life Science Products, Boston, MA, USA) membrane and cross-linking in a Stratagene ${ }^{\circledR}$ Stratalinker ${ }^{\circledR}$ (Stratagene, La Jolla, CA, USA) were performed as previously described (4). The membrane was scanned wet using a Storm 860 Instrument set for blue fluorescence and a photomultiplier voltage of 
900. After drying the membrane under forced air at $65^{\circ} \mathrm{C}$ for $30 \mathrm{~min}$ in a hybridization oven (Techne, Cambridge, England, UK), the scanning was repeated. A human GAPDH cDNA (7) probe was labeled by random primed synthesis using $\left[\alpha^{32} \mathrm{P}\right] \mathrm{dCTP}$ and a Mega Prime Kit from Amersham Pharmacia Biotech (Buckinghamshire, England, UK) to a specific activity of $1.03 \times 10^{9} \mathrm{cpm} / \mu \mathrm{g}$. Hybridization and progressively stringent washes were carried out as described previously $(4,8)$ to a final wash with $15 \mathrm{mM} \mathrm{NaCl}$, $1.5 \mathrm{mM}$ sodium citrate and $0.1 \%$ SDS (Life Technologies, Rockville, MD, USA) at $60^{\circ} \mathrm{C}$. Detection was accomplished by exposing the membranes to phosphor screens (Molecular Dynamics) for 24,48 or $96 \mathrm{~h}$ and imaging with the Storm 860 Instrument. ImageQuant $^{\mathrm{TM}}$ (Molecular Dynamics) software was used for quantitation.

The results of the ethidium bromide staining and GAPDH probing of the same membrane are compared in Figures 1 and 2. Figure 1 shows the images of the membranes from the Storm 860 instrument. The fluorescent image resulting from scanning the membrane wet is shown. Scanning the membrane dry (data not shown) increased the signal but offered negligible advantage over scanning the membrane wet as the background increased proportionally. Plots of the relative signal for the GAPDH phosphorimage and ethidium bromide fluorescence (in the $18 \mathrm{~S}$ and in the $28 \mathrm{~S}$ ribosomal RNA bands) versus total RNA loaded are shown for the small well (Figure 2A) and the large well (Figure 2B) loading configurations. Both the fluorescence and the phosphorimage data were linearly related to loading throughout the entire range. Extending exposures of the phosphor screens from 24 to 48 or $96 \mathrm{~h}$ increased the signal intensity but did not alter linearity (data not shown). Linear regression analysis between ethidium bromide fluorescence in either rRNA band and the GAPDH phosphorimage counts (Figure 2, C and D) demonstrates a very close correlation between the two methods for the estimation of loading. When the small wells were loaded (range $0.5-5 \mu \mathrm{g}$ total $\mathrm{RNA} /$ lane), the $\mathrm{R}^{2}$ values for the ethidium bromide $18 \mathrm{~S}$ and $28 \mathrm{~S}$ bands versus GAPDH were 0.95 and 0.92 , respectively (Figure 2C). When the larger wells were loaded (range 5-25 $\mu$ g total $\mathrm{RNA} /$ lane), the $\mathrm{R}^{2}$ values for the ethidium bromide $18 \mathrm{~S}$ and $28 \mathrm{~S}$ bands versus GAPDH were 0.93 and 0.94 , respectively (Figure 2D).

Not only was it possible to obtain an image of the ethidium bromide-stained membrane directly from the Storm 860 Instrument (despite the excitation wavelength being far from optimal) but also the quantitation of that image was 

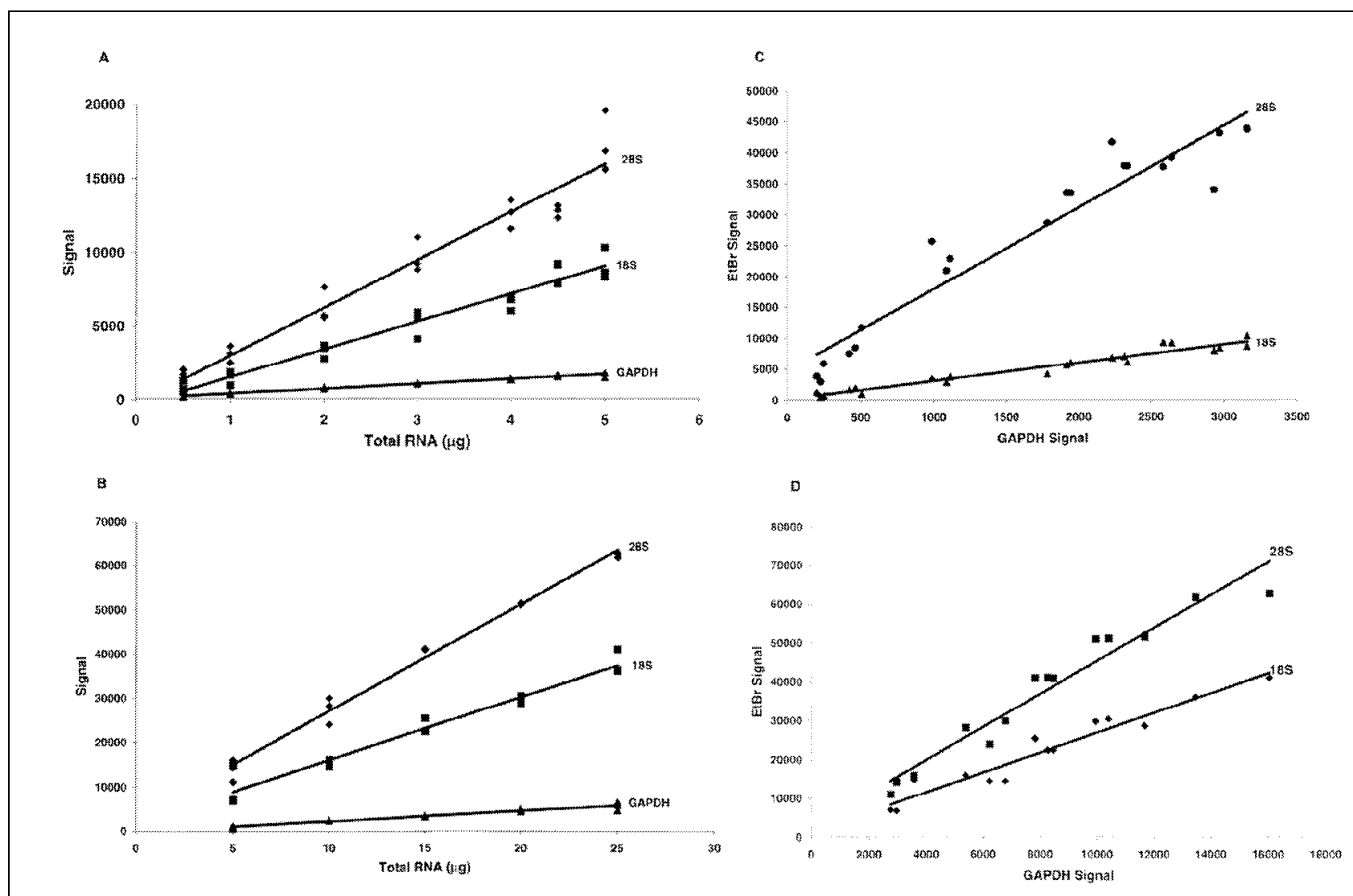

Figure 2. Comparison of RNA quantification by optical scanning of a Northern blot stained with ethidium bromide and subsequently probed with GAPDH. (A) Computer-assisted fluorometric image densitometry of ethidium bromide-stained 18S and 28S rRNA and phosphorimage densitometry of mRNA probed with GAPDH (0.5-5 $\mu \mathrm{g}$ total RNA/lane); (B) the same as in panel A (5-25 $\mu \mathrm{g}$ total RNA/lane); (C) linear regression of ethidium bromide (EtBr) fluorometric image densitometry vs. GAPDH phosphorimage densitometry (0.5-5 $\mu \mathrm{g}$ total RNA/lane); (D) the same as in panel C (5-25 $\mu \mathrm{g}$ total RNA/lane). In all graphs, $P<0.0001$.

equivalent to quantitation of the image of the GAPDH probed membrane. The $\mathrm{R}^{2}$ values when compared to those obtained with GAPDH were all above 0.9. Notably, the linear range for ethidium bromide was not exceeded in these experiments. We have recently used the method described in normalization of a membrane that was probed for transcription factor PPAR $\gamma$ (3). PPAR $\gamma$ was consistently detected in 30 placental RNA samples. Hybridization efficiency was comparable to or better than hybridization on a membrane that had been photographed on a $312 \mathrm{~nm}$ UV light box before hybridization (5).

The typical problems associated with using ethidium bromide for normalization were all eliminated. There was no need for a photograph or negative, and nonuniform illumination by the lightbox and scanner was no longer an issue. The limit of detection for transferred RNA by the method described was less than $0.5 \mu \mathrm{g}$ total RNA per lane in the small wells when either rRNA band was used for quantification. The use of a Spectroline ${ }^{\circledR}$ UV transilluminator (Spectronics, New York, NY, USA), photography with Polaroid ${ }^{\circledR}$ type 665 film and a Microtek ${ }^{\mathrm{TM}}$ ScanMaker X6el (Microtek Laboratories, Redondo Beach, CA, USA) to scan the negative image produced a limit of detection between 0.5 and $1.0 \mu \mathrm{g}$ total RNA (data not shown). If the ethidium bromide is added to the RNA sample at the time of gel loading, there is no need to stain and destain. The membrane can be scanned directly after preparation using an optical scanning instrument such as the Storm 860 Instrument. While we used this product from Molecular Dynamics, product information from several other companies boasts a wavelength range equally or even more suitable for this purpose. This approach will be superior to using GAPDH for normalization because rRNA is commonly believed to be less variable with treatment conditions and an independent estimate of its variation can be derived by comparing total RNA yield to cell number or DNA yield. Furthermore, in this type of experiment, it is typically the appropriate loading control because the assumption that rRNA does not vary is made when RNA is loaded by quantity.

\section{REFERENCES}

1.Haugland, R.P. 1996. Handbook of Fluorescent Probes and Research Chemicals, p. 144156. M.T.Z. Spence (Ed.), Molecular Probes, Eugene, OR. 
2.Hayflick, L. 1961. The establishment of a line (WISH) of human amnion cells in continuous cultivation. Exp. Cell Res. 23:14-20.

3.Marvin, K.W., R.L. Eykholt, J.A. Keelan, T.A. Sato and M.D. Mitchell. The 15-deoxydelta12,14 prostaglandin $\mathrm{J} 2$ receptor, peroxisome proliferator activated receptor-gamma (PPAR-gamma) is expressed in gestational tissues and is functionally active in JEG3 choriocarcinoma cells. Placenta 21:115-121.

4.Marvin, K.W., H.R. Hansen, H.C. Miller, R.L. Eykholt and M.D. Mitchell. 1999. Amnion-derived cells express intercellular adhesion molecule-1: regulation by cytokines. J. Mol. Endocrinol. 22:193-205.

5.Ogretmen, B., H. Ratajczak, A. Kats, B.C Stark and S.M. Gendel. 1993. Effects of Staining of RNA with ethidium bromide before electrophoresis on performance of Northern blots. BioTechniques 14:932-935.

6.Sambrook, J., E.F. Fritsch and T. Maniatis. 1989. Molecular Cloning: A Laboratory Manual, 2nd ed., CSH Laboratory Press, Cold Spring Harbor, NY.

7.Tso, J.Y., X.Hm. Sun, T.H. Kao, K.S. Reece and R. Wu. 1985. Isolation and characterization of rat and human glyceraldehyde-3-phosphate dehydrogenase cDNAs: genomic complexity and molecular evolution of the gene. Nucleic Acids Res. 13:2485-2502.

8.Vollberg, T.M., Sr., M.D. George and A.M. Jetten. 1991. Induction of extracellular matrix gene expression in normal human keratinocytes by transforming growth factor $\beta$ is altered by cellular differentiation. Exp. Cell Res. 193:93-100.

The authors would like to thank Dr. Leslie Myatt from the University of Cincinnati for the generous gift of WISH cells. The work was supported by Grant No. 97/017 from the Health Research Council of New Zealand, Grant No. UOA-605 from The Royal Society of New Zealand Marsden Fund and Grant No. AP 57964 from the New Zealand Lottery Grants Board. Address correspondence to Roberta $L$. Eykholt, Department of Pharmacology and Clinical Pharmacology, Faculty of Medical and Health Sciences, University of Auckland, Private Bag 92019, Auckland, New Zealand. Internet: r.eykholt@auckland.ac.nz.

Received 18 October 1999; accepted 21 January 2000.

\section{Roberta L. Eykholt, Murray D. Mitchell and Keith W. Marvin Faculty of Medical and Health Sciences University of Auckland Auckland, New Zealand}

\section{Accelerated Titering of Adenoviruses}

BioTechniques 28:870-873 (May 2000)

In recent years, adenovirus (Ad) vectors have become a popular tool, particularly for in vivo gene transfer applications. Following construction of a new Ad vector, quantification of the viral infectious unit by plaque titering is a standard step in the characterization of any newly generated virus stock. However, the management of the plaque assay is cumbersome and takes between 4 and 10 days. In addition, interpretation of the results is often complicated by the variability in size and shape of plaques. The fluorescent focus assay accelerates the speed necessary for determining adenovirus titers and is a common test in adenovirus applications $(1,3,5,8)$. This assay takes only two days to obtain results. Although counting infected cells is easy, the procedure requires a suitable environment (dark) and expensive equipment (fluorescent microscopy for cell culture dishes). In addition, comparisons between the fluorescent focus assay and standard plaque assay in titering adenovirus are not available yet. We present a modified technique for an easy, reliable and fast determination of adenovirus titers, the "spot assay".

Viruses used for the titer experiments were AdCMV.Null (2), AdCMV.NLSBgal (4), AdCMV.RiboI and AdCMV. RiboIV (both expressing ribozymes against $\alpha$-galactosyl transferase) and AdCMV.antiGT (expressing an antisense structure against $\alpha$-galactosyl transferase). Recombinant adenoviruses were prepared as previously described $(2,6)$. For the plaque assay, 293 cells were grown as monolayers on 6-well culture dishes and maintained in DMEM with 5\% fetal calf serum (FCS). Plates were set up at least in duplicate. At a density of $70 \%-80 \%$, medium was removed and cells were infected with $100 \mu \mathrm{L}$ of six different virus dilutions (viral stock solution diluted $1: 10^{7}$ to $1: 10^{12}$ in serum-free medium). Incubation at $37^{\circ} \mathrm{C}$ was maintained for $1.5 \mathrm{~h}$ with repeated rocking of the plates. Then complete medium with 5\% FCS was added. After $24 \mathrm{~h}$, culture medium was removed and replaced by $7.5 \mathrm{~mL}$ 